\title{
Erratum to: Discussing euthanasia in two German states: scientific terminology and public discourse in the German Democratic Republic and the Federal Republic of Germany
}

\author{
Hartmut Bettin · Andreas Nowak · Maria Grazia Roccia · Sabine Salloch
}

Published online: 16 October 2017

(c) Springer-Verlag GmbH Austria 2017

\section{Erratum to:}

Wien Med Wochenschr 2017

https://doi.org/10.1007/s10354-017-0591-1

The original version of this article unfortunately contained a mistake. The spelling of the Maria Grazia Roccia's name was incorrect.

Conflict of interest H. Bettin, A. Nowak, M.G. Roccia, and S. Salloch declare that they have no competing interests.

The online version of the original article can be found under https://doi.org/10.1007/s10354-017-0591-1.

H. Bettin, MD $(\bowtie) \cdot$ S. Salloch, MD, PhD Institute for Ethics and History of Medicine, University Medicine Greifswald, Greifswald, Germany hartmut.bettin@uni-greifswald.de

S. Salloch, MD, PhD

sabine.salloch@uni-greifswald.de

A. Nowak, MD

Department of Anesthesiology \& Intensive CareMedicine,

Emergency Medicine \& Pain Management, Dresden, Germany

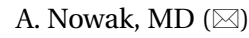

Friedrichstadt Hospital, Dresden University Teaching Hospital, Friedrichstrasse 41, 01067 Dresden, Germany nowak-an@khdf.de

\section{G. Roccia, MD ( $ه)$}

Public Health and CommunityMedicine, Department of

Technology, Communication and Society Gugliemo

Marconi, University Rome, Rome, Italy

mgrroccia@gmail.com 